\title{
Prof. Dr. José Manuel Borgoño Domínguez
}

\author{
Enrique Laval $R$.
}

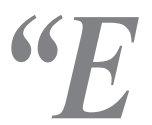

l doctor José Manuel Borgoño Domínguez, destacado ex-alumno nuestro en la Pontificia Universidad Católica primero y en la Escuela de Salubridad después, ingresó a nuestro equipo en 1952, para colaborar especialmente en la docencia. Posteriormente aquella se extendió a lo asistencial y a la investigación. El doctor Borgoño une a su inteligencia, una activa y sana ambición que le han permitido desarrollar, en forma paralela, con laboriosidad y entusiasmo, una excelente carrera docente y funcionaria: profesor de Higiene $y$ Medicina Preventiva en la Universidad de Chile y cargos importantes en organismos internacionales de Salud Pública. Ha sido siempre un excelente colaborador y leal amigo".

Con estas palabras el profesor Roque Kraljevic, trazó en su libro "Memorias de un viejo infectólogo", publicado en 1998, algunas de las características que adornaron la personalidad inconfundible de José Manuel Borgoño, quien por 18 años, colaboró infatigablemente en la consolidación y prestigio del Pabellón de Enfermedades Infecciosas del Hospital Ramón Barros Luco y luego, desde 1963, Hospital de Enfermedades Infecciosas Profesor Doctor Lucio Córdova ${ }^{1}$.

Quiero destacar justamente en esta oportunidad la importante contribución de José Manuel al desarrollo de la especialidad en nuestro medio. Recuerdo una frase suya que tiene toda la fuerza y sello de su visión de la Salud Pública y de la Epidemiología: "un médico epidemiólogo debe conocer en forma profunda y detallada la clinica de las enfermedades infecciosas, como parte importante de su formación".

Esto fue lo que condujo a José Manuel a hacer de nuestro hospital su "segundo hogar", donde se integró con entusiasmo a todas sus actividades: médico clínico docente, con gran participación en la realización de clases teóricas y prácticas a los alumnos de la Universidad de Chile y de la Pontificia Universidad Católica. A tanto alcanzó su cariño e interés por "su hospital", que junto con varios del equipo médico participó en los "turnos de noche", en la década del 60, sin retribución económica, siguiendo la "profunda y lapidaria admonición" del profesor Kraljevic sobre la "experiencia riquísima que constituía el enfermo febril en la noche"2.

José Manuel Borgoño nació el 6 de agosto de 1924,

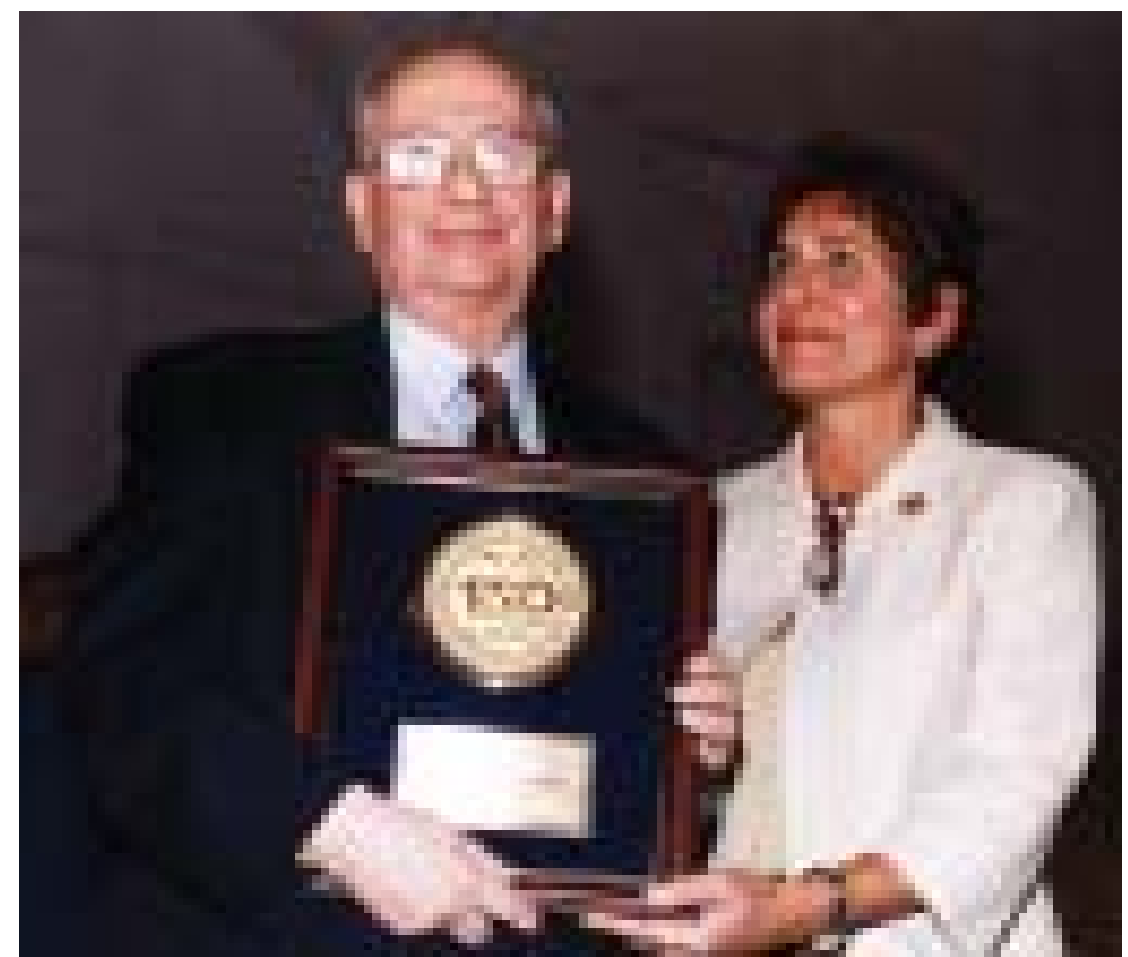

Dra. Ana Cristina Nogueira, representante de la OPS/OMS en Chile (período 19982002), entrega reconocimiento al Dr. J. Manuel Borgoño, con ocasión del centenario de la institución. notoriamente, obteniendo zó sus estudios médicos en la Facultad de Medicina de la Pontificia Universidad Católica y los dos últimos años los continuó en la Universidad de Chile, recibiendo el título de médico el año $1950^{3}$.

Además de la intensa labor desarrollada a nivel del Ministerio de Salud y de las obligaciones que lo hacían efectuar frecuentes viajes al extranjero para representar al país en la OPS o en la OMS por nombrar las más importantes, José Manuel Borgoño, como ya se mencionó, trabajó en el Hospital de Enfermedades Infecciosas durante 18 años. Junto con su actividad clínica docente, efectuó trabajos de investigación sobre clínica, epidemiología y terapéutica especialmente sobre fiebre tifoidea y paratifoidea. Además publicó reseñas de los primeros casos de psitacosis y de

Correspondencia a: Enrique Laval Román sochinf@sochinf.cl 
pleurodinia epidémica comprobados en Chile, como también sobre primeros ensayos de tratamiento con fenoximetil penicilina por vía oral en la neumonía neumocóccica y comprobación de la eficacia de la combinación de tetraciclina y oleandomicina en diversos procesos infecciosos. Mostró gran interés por la revisión de la casuística de meningitis con líquido céfalo-raquídeo claro no tuberculosa y en 1957 participó en el simposio sobre la epidemia de influenza en Santiago, con la publicación de un análisis clínico de la enfermedad y sus complicaciones en el adulto.

El síndrome muco-cutáneo-ocular (StevensJohnson), que se caracteriza por un cuadro febril con compromiso del estado general y participación, en grado variable, del aparato respiratorio, de la piel y de las mucosas, fue motivo para que diera a conocer los 18 enfermos con este cuadro atendidos entre diciembre de 1949 y octubre de 1950, en el hospital, destacando la importancia del diagnóstico correcto, con el fin de efectuar un tratamiento precoz que evitara complicaciones y secuelas que podían ser graves.

En casi todas estas publicaciones José Manuel participó junto con otros miembros del equipo médico, siendo muchas veces el motor que impulsaba la terminación prolija y acuciosa del trabajo.

Si bien he mencionado sólo una parte de la labor de José Manuel Borgoño, creo conveniente señalar entre sus artículos editoriales en Revista Chilena de Infectología, el dedicado a "Sarampión: pasado, presente y futuro", publicado en 1997. Ahí manifiesta que en "Chile falta experiencia para el diagnóstico clínico, porque debido al control epidemiológico de la enfermedad, muchos médicos no han visto casos de sarampión. Por otra parte, los programas de vacunación hacen que existan casos clínicos atípicos o muy benignos que dificultan su identificación, por lo que siempre, en un adecuado programa de control y eliminación de la enfermedad, debe haber un grupo de médicos con experiencia que sirvan de referencia para confir- mar estos diagnósticos e indicar el apoyo necesario de laboratorio para la certeza virológica del diagnóstico" ${ }^{\prime-17}$.

Finalmente, en el último escrito de José Manuel Borgoño en Revista Chilena de Infectología en 2002, sobre "Vacunación antivariólica", relata brevemente la historia de dicha vacunación, realzando que en mayo de 1980 la OMS certificó la erradicación de la viruela en el mundo, hito extraordinariamente importante en la historia de la medicina y que el doctor Borgoño tuvo el privilegio de firmar el acta, en representación de Chile, de este hecho trascendental ${ }^{18}$.

En 1950, José Manuel Borgoño viajó por un año y medio a los Estados Unidos a cursar el Master en Salud Pública en Johns Hopkins University, a través de una beca de la Fundación Rockefeller. Con posterioridad fue becado para perfeccionamiento a Cleveland y Berkeley en los Estados Unidos de América por la Agencia Internacional del Desarrollo y a Mac Master en Canadá por la Fundación Kellog.

El doctor Borgoño fue Socio Fundador de la Sociedad Chilena de Infectología (recibió el título de Socio Honorario), de las sociedades chilenas de Salubridad, Epidemiología y Medicina Familiar.

En 1985, recibió el reconocimiento del Fondo de las Naciones Unidas para la Infancia (UNICEF) y en 1988, la medalla de Salud para Todos otorgada por la OMS, siendo el único chileno que la ha obtenido a título personal. En el año 2002, recibió el Premio Centenario de la OPS por su trabajo internacional por la Salud del Mundo.

En palabras de la Dra. Segovia, que suscribo con todo respeto y cariño: "el doctor Borgoño no pasa inadvertido...sino deja una profunda huella...no importando dónde y con quién se relaciona... el que lo conoció no lo olvida"3.

José Manuel Borgoño, después de una larga y penosa enfermedad, falleció en Santiago, el 16 de diciembre de 2004.

\section{Referencias}

1.- Kraljevic, O.R. Memorias de un viejo infectólogo. 1998. Stgo. Chile. p.63.

2.- Laval, R. E. Recuerdos del doctor José Manuel Borgoño. (inéditos).

3.- Segovia, I. Semblanza del Prof. Dr. José Manuel Borgoño. Huella y Presencia. Fac. de Medicina. Univ. de Chile. Tomo VI. Impta. Andros, 2004. p. 233-8.

4.- Kraljevic O R, Borgoño J M, Sesnic R, González O, Mac Guinty A. Estudio clínico y epidemiológico de primer brote de psitacosis humana comprobado en Chile. Rev Méd
Chile 1957; 85: 222-5.

5.- Kraljevic O R, Borgoño J M, Laval E. Therapeutic trial of oral phenoxymethyl penicillin in pneumococcal pneumonia. AM and CT. 1958; 5: 189-96.

6.- Kraljevic O R, Pearson E, Borgoño J M. Investigación del valor terapéutico de la combinación tetraciclina y oleoandomicina. (Presentado en sesión de la Sociedad Médica de Santiago del 6 de Junio de 1958).

7.- Kraljevic O R, Borgoño J M, Contreras G. Estudio clínico de la pleurodinia epidémica. Comprobación etiológica por primera vez en Chile. Rev Méd Chile 1958; 86: 667-71.
8.- Kraljevic O R, Borgoño J M, Sesnic R. Estudio clínico y epidemiológico de los paratifus A y B. Rev Méd Chile 1960; 88: 324-34.

9.- Meneghello J, Borgoño J M, Rodríguez M, Salcedo M, Tello A. Meningitis aséptica. Mesa redonda. Coordinador: R. Kraljeviæ. Rev Méd Chile 1960; 88: 358-66.

10. - Kraljevic O R, Salcedo M, Borgoño J M, Laval E. Síndrome muco-cutáneo-ocular (Stevens-Johnson). Análisis de 18 casos. Rev Méd Chile. 1961; 89: 3-8.

11.- Kraljevic O R, Salcedo M, Borgoño J M, Laval E. Meningitis con LCR claro, no 
tuberculosas. Análisis de 112 casos. Rev Méd Chile 1961; 89: 3-8.

12.- Kraljevic O R, Borgoño J M. Tratamiento de las septicemias. Rev Méd Chile 1961: 293-7.

13.- Kraljevic O R, Paredes L, Philippi F, Borgoño J M. Nuevas penicilinas. Mesa Redonda. Coordinador: R. Valdivieso. Rev Méd Chile 1964; 91: 338-52.
14.- Borgoño J M, Pearson E. Fiebre tifoidea y paratifoidea. Análisis clínico y de laboratorio de un brote estacional. Rev Méd Chile 1965; 93: 145-51.

15.- Salcedo M, Borgoño J M, Greber R, Lobos H, Hazbun M, Solari G. Tratamiento de la fiebre tifoidea y paratifus con trimetoprim y sulfametoxazol. Rev Méd
Chile 1972; 100: 1064-7.

16.- Borgoño J M. Meningitis purulenta: un problema de siempre. Rev Méd Chile 1993; 121: 199-200.

17.- Borgoño J M. Sarampión: pasado, presente y futuro. Rev Chil Infect 1997; 14: 71-3.

18.- Borgoño J M. Vacuna antivariólica. Rev Chil Infect 2002; 19: 60-2.

\title{
Relato
}

\section{Harina de otro costal}

\author{
Bruno Bisconti*
}

Vittorio Capra, a quien todos llamaban Vito, había decidido esa mañana después de diez años de arduo trabajo, abandonar el hospital que tanto amaba y que lo había formado como pediatra. Atrás quedarían los grandes maestros, las reuniones clínicas de los casos de difícil diagnóstico, los turnos de Navidad y Año Nuevo, las carreras por las escaleras para asistir a un niño en paro cardiorrespiratorio y los amigos de tantas jornadas. La reunión habitual del "Servicio de Infecciosos" de los días viernes había terminado, y supo en ese instante que ésta sería su última reunión. Su camino debía continuar lejos de la capital, a pesar de haber logrado posicionarse como un respetado y digno integrante de la familia hospitalaria del más prestigioso hospital pediátrico de su país.

Desde la terraza del cuarto piso, transformada en sala de reuniones, miraba impávido el avance de la negra nube que comenzaba a cubrir el cielo de la gran ciudad como un manto amenazante que inevitable-

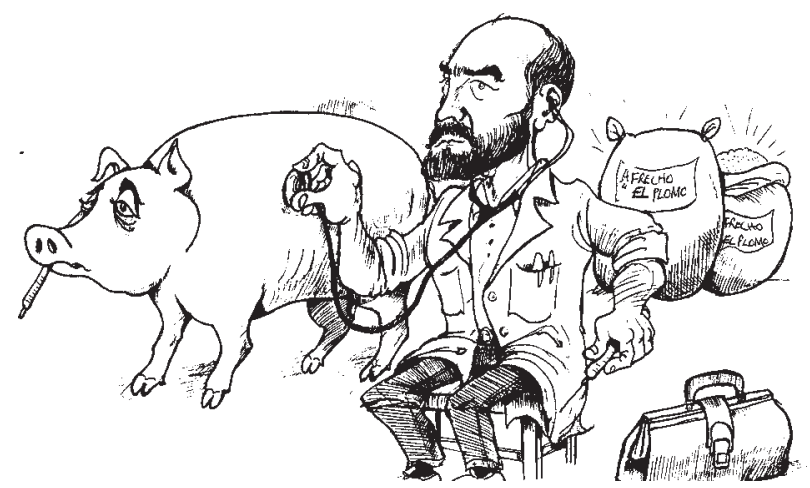

para enfrentar los nuevos desafíos, y abordar los problemas, por difíciles que estos fueran. No sólo contaba con el respaldo de sus conocimientos, sino también con el apoyo incondicional de los viejos amigos y de toda su familia.

A las seis de la tarde cerró la puerta de su oficina dejando en su interior las sonrisas de cientos de niños que lo habían conocido, y se llevó en el alma sus tiernas miradas. Se despidió de su secretaria que lo había acompañado por años, y quedó flotando en el ambiente el eco de sus últimas palabras.

- Adiós doctor, que le vaya bien y venga a verme.

No era el momento para sentimentalismos. En sus hombros pesaba la decisión que había tomado y sabía que éste era un camino sin retorno. $\mathrm{Se}$ dirigió a la notaría de Don Joaquín Vega donde lo esperaba el Dr. Guglielmo Centofuochi. Subió las escaleras con paso firme y después de leer el documento de compraventa estampó su firma, sellando así la firme decisión de migrar. Res- 